\title{
An efficient induction protocol for deriving mature oligodendrocytes from human dental stem cells
}

\author{
Bagheri-Hosseinabadi $\mathrm{Z}^{1}$, Ghasemi Hamidabadi $\mathrm{H}^{2}$, Nazm Bojnordi $\mathrm{M}^{2}$ \\ Department of Clinical Biochemistry, School of Medicine, Rafsanjan University of Medical Sciences, \\ Rafsanjan, Iran. bojnordi@modares.ac.ir
}

\begin{abstract}
INTRODUCTION: This study examined the process of deriving mature oligodendrocytes from human dental pulp stem cells (hDPSCs) via addition of cerebrospinal fluid (CSF).

METHODS: The hDPSCs were cultured in the presence of retinoic acid and CSF. The oligodendrocytes were confirmed using immunocytochemistry for specific glial markers, namely Olig2 and MBP markers.

RESULTS: The differentiated oligodendrocytes were immunopositive for Olig2 and MBP markers at the end of induction phase.

CONCLUSION: It is concluded that this study indicated the glial differentiation of hDPSCs in the presence of CSF and appropriate inducers, which is a usable therapeutic technique in neuroregenerative medicine (Fig. 3, Ref. 24). Text in PDF www.elis.sk.

KEY WORDS: human dental pulp stem cells, oligodendrocyte, cerebrospinal fluid, retinoic acid.
\end{abstract}

\section{Introduction}

Oligodendrocytes form the myelin sheet which surrounds the axons. The impairment of these cells disrupts the myelin structure and leads to severe neurological symptoms (Grade et al, 2013; Czepiel et al, 2015). Cell therapy is considered an efficient method to improve remyelination in demyelination diseases such as multiple sclerosis (MS) (Chang et al, 2014; Bojnordi et al, 2017). Among various types of stem cells, human dental pulp stem cells are recognized as a novel noninvasive source with the property of neuroglial differentiation under in vitro culture conditions (Sloan et al, 2007; Gronthos et al, 2002). However, in vitro culture derivation of mature oligodendrocytes is accompanied with some limitations. Cerebrospinal fluid (CSF) can promote the neuroglial differentiation of mesenchymal stem cells (Johanson et al, 2008; Miyan et al, 2003). Nevertheless, the effect of CSF on in vitro differentiation of hDPSC to glial differentiation has not been investigated so far. Therefore, the aim of our study was to evaluate the differentiation potential of hDPSC into oligodendrocytes in the presence of glial inducers and CSF.

${ }^{1}$ Department of clinical Biochemistry, School of medicine, Rafsanjan University of Medical Sciences, Rafsanjan, Iran, and ${ }^{2}$ Immunogenetic Research Center, Department of Anatomy \& Cell Biology, Faculty of Medicine, Mazandaran University of Medical Sciences, Sari, Iran

Address for correspondence: M. Nazm Bojnordi, Immunogenetic Research Center, Department of Anatomy and Cell Biology, Faculty of Medicine, Mazandaran University of Medical Sciences, Sari, P.O. Box: 4847191971, Iran.

Phone: +011.33543080

Acknowledgments: The authors thank the Mazandaran University of Medical Sciences for financial support of this project.
Based on the fact that the enrichment plexus of CSF consists of various growth elements and essential factors, we used CSF and designed an efficient culture system by adding CSF to a cocktail of inducers. Our culture system is usable as an alternative procedure leading to significant enhancement in the process of generating oligodendrocytes from BMSC.

\section{Material and methods}

\section{CSF Collection}

Rat embryos were used for collecting CSF in each experiment. Cerebrospinal fluid was isolated from cisterna magna (Lee et al, 2012).

\section{Morphological characterization of cultured hDPCs}

The hDPSCs were collected from human dental pulp of molar teeth in Mazandaran University of Medical Sciences. After mechanical and enzymatic digestion, the cells were cultured and cell proliferation and morphological changes of hDPSCs were monitored daily via phase contrast microscopy. The morphological changes of differentiated glial cells were evaluated during the differentiation period.

Flow cytometry of mesenchymal surface markers

At the fourth passage, the hDPSCs were immunostained for mesenchymal surface markers antibodies, namely CD90, CD44 and CD73.

\section{Differentiation of hDPSCs in to oligodendrocyte}

The hDPSCs were cultured in DMEM/F12 medium, $10 \mathrm{ng} / \mathrm{ml}$ epidermal growth factor (EGF), $1 \mu \mathrm{M}$ retinoic acid (RA), $20 \mathrm{ng} / \mathrm{ml}$ 
basic fibroblast growth factor (bFGF) for 4-6 days. This procedure was followed by adding CSF. Addition of CSF to medium was done daily for 8-10 days (Kaka et al, 2012).

\section{Immunocytochemical evaluation with fluorescence microscopy}

Immunocytochemistry technique was performed to confirm the differentiated oligodendrocytes. The specific oligodendrocyte markers, e.g. Olig2 and MBP were investigated. The stained cells were evaluated via fluorescent microscope.

\section{Statistical analysis}

Dates were analyzed using one-way analysis of variance test (ANOVA) and (SPSS 13.0 software, while $\mathrm{p}<0.05$ was considered significant.

\section{Results}

\section{Characterization of $h D P S c$}

The hDPSCs appeared to gain the spindle fibroblastic morphology typical for mesenchymal stem cells (Fig. 1). The flow cytometry data proved hDPSCs to be immunopositive for mesenchymal markers, namely CD 44, CD 90, and CD 105 (Moayeri et al, 2017).

\section{Differentiation of hDPSCs into mature oligodendrocytes}

The differentiation of hDPSCs to oligodendrocytes was confirmed by glial structure. The differentiated cells exposed to CSF showed the specific morphological changes as shown whith phase contrast microscopy (Fig. 2). Also, the glial differentiation into oligodendrocytes was confirmed by immunostaining the specific glial markers, namely Olig2 and MBP (Fig. 2).

After counting, the mean percentages of cells immunopositive for Olig2 and MBP were 47.25 $\pm 0.15 \%$ and $45.12 \pm 1.75 \%$, respectively.
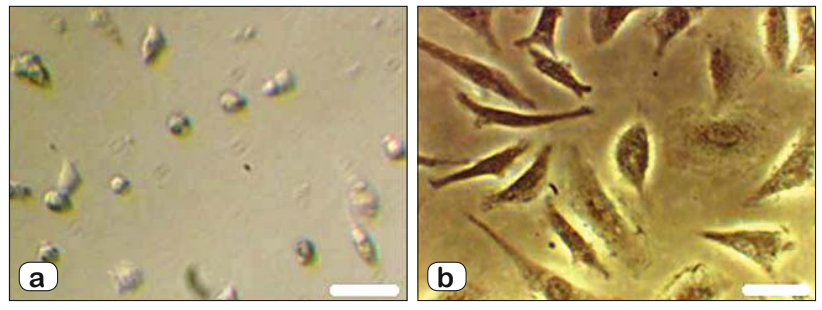

Fig. 1. The morphology of human dental pulp stem cells cultured in vitro. a: Primary culture, b: 4th passage culture. Scale bars $40 \mu \mathrm{m}$.
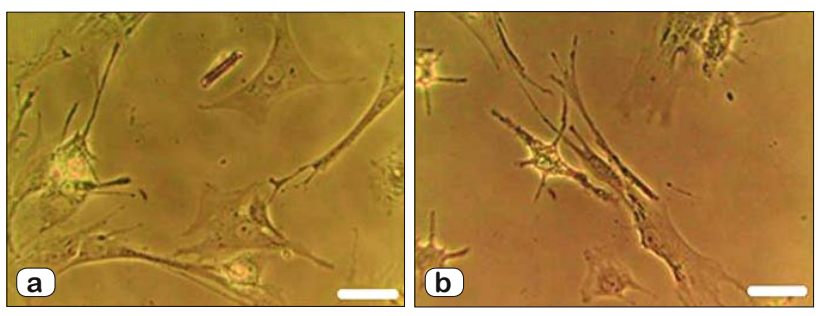

Fig. 2. Differentiation of human Dental pulp stem cells to Oligodendrocyte in vitro. a: Oligoprogenitor cells' morphology, b: Glial differentiation in the presence of CSF. Scale bars $40 \mu \mathrm{m}$.
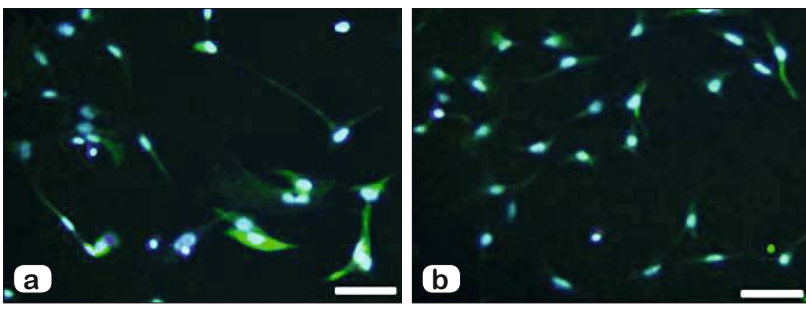

Fig. 3. Immunostaining for differentiated oligodendrocyte. Fluorescence photos of olig2 (a) and MBP (b) in treated group. Scale bars $10 \mu \mathrm{m}$.

\section{Discussion}

The hDPSCs have a therapeutic potential in neural tissue engineering and neuroregenerative medicine based on their ability in neuroglial differentiation (Gronthos et al, 2000, Huang et al, 2008). The hDPSCs are multipotent stem cells that arise from neural crest and have the ability to differentiate into neurons and oligodendrocytes.

These characteristics predispose them to become an applicable cell source in cell therapy for neurodegenerative diseases (Alizadeh et al, 2017, Chun et al, 2016). In vitro differentiation of oligodendrocytes from hDPSCs depends on various differentiation procedures with different inducers. In our study, we have designed an efficient culture condition for oligodendrocytes differentiation by adding CSF.

CSF contains a variety of growth factors and natural nutrients, which provides a niche that is similar to extracellular matrix of neural networks. These properties improve the maturation and differentiation processes of stem cells or progenitor cells (Yalvac et al, 2009, Haratizadeh et al, 2016, Yang et al, 2009; Ye al, 2012,).

Our results showed that hDPSCs appeared to gain fibroblastic morphology and high adherent potential, which is in agreement with previous researches (Martens et al, 2014; Song et al, 2002; Mattei et al, 2015; Gervois et al, 2015).

We observed that hDPSCs can be differentiated into mature oligodendrocytes in the presence of CSF, the fact of which can be used in promoting remyelination in frame of therapeutic strategies applied in neuroregenerative medicine.

\section{References}

1. Grade S, Bernardino L, Malva JO. Oligodendrogenesis from neural stem cells: perspectives for remyelinating strategies. Int J Dev Neurosci 2013; 31: 692-700.

2. Czepiel ME, Boddeke E, Copray S. Human oligodendrocytes in remyelination research. Glia 2015; 63: 513-530.

3. Chang CC, Chang KC, Tsai SJ, Chang HH, Lin CP. Neurogenic differentiation of dental pulp stem cells to neuron-like cells in dopaminergic and motor neuronal inductive media. J Formos Med Assoc 2014; 113 (12): 956-965.

4. Bojnordi MN, Azizi H, Skutella T, Movahedin M, Pourabdolhossein F, Shojaei A et al. Differentiation of spermatogonia stem cells into functional mature neurons characterized with differential gene expression. Mol Neurobiol 2017; 54 (7): 5676-5682. 
5. Sloan AJ, Smith AJ. Stem cells and the dental pulp: potential roles in dentine regeneration and repair. Oral Dis 2007; 13: 151-157.

6. Gronthos S, Brahim J, Li W, Fisher LW, Cherman N, Boyde A et al. Stem cell properties of human dental pulp stem cells. J Dent Res 2002; 81 (8): 531-535.

7. Johanson CE, Duncan JA, Klinge PM et al. Multiplicity of cerebrospinal fluid functions: New challenges in health and disease. Cerebrospinal Fluid Res 2008; 5: 10.

8. Miyan JA, Nabiyouni M, Zendah M. Development of the brain: a vital role for cerebrospinal fluid. Can J Physiol Pharmacol 2003; 81: 317-328.

9. Li Y, Zhang B, Wen W et al. The comparison of three methods of drawing cerebrospinal fluid in rabbit. J Neurosci Methods 2012; 209: 398-402.

10. Kaka GR, Tiraihi T, Delshad A et al. In vitro differentiation of bone marrow stromal cells into oligodendrocyte-like cells using triiodothyronine as inducer. Int J Neurosci 2012; 122: 237-247.

11. Moayeri A, Bojnordi MN, Haratizadeh S, Esmaeilnejad-Moghadam A, Alizadeh R, Hamidabadi HG. Transdifferentiation of human dental pulp stem cells into oligoprogenitor cells. Basic Clin Neurosci 2017; 8 (5): 387.

12. Gronthos S, Mankani M, Brahim J, Robey PG, Shi S. Postnatal human dental -pulp stem cells (DPSCs) in vitro and invivo. Proc Nat Acad Sci 2003; 97 (25): 13625-13630.

13. Huang AHC, Chen YK et al. Isolation and characterization of dental pulp stem cells from a supernumerary tooth. J Oral Pathol Med 2008; 37: $571-574$

14. Alizadeh R, Hassanzadeh G, Joghataei MT, Soleimani M, Moradi F, Mohammadpour $\mathbf{S}$ et al. In vitro differentiation of neural stem cells derived from human olfactory bulb into dopaminergic-like neurons. Eur J Neurosci 2017; 45 (6): 773-784.

15. Chun SY, Soker S, Jang YJ, Kwon TG, Yoo ES. Differentiation of Human Dental Pulp Stem Cells into Dopaminergic Neuron-like Cells in Vitro. J Korean Med Sci 2016; 31 (2): 171-177.
16. Yalvac ME, Rizvanov AA et al. Potential role of dental stem cells in the cellular therapy of cerebral ischemia. Curr Pharm Des 2009; 15: 3908-3916.

17. Song H, Charles S, Fred G. Neural stem cells from adult hippocampus develop essential properties of functional CNS neurons. Nature Neurosci 2002; 5: 438-445.

18. Ye Y, Zeng YM, Wan MR, Lu XF. Induction of human bone marrow mesenchymal stem cells, differentiation into neural-like cells using cerebrospinal fluid. Cell Biochem Biophys 2011; 59: 79-84.

19. Yang HY, Gu R, Wang WJ, Gao ZL. The cerebrospinal fluid promotes the differentiation of neural stem cells after transplantation of bone marrow mesenchymal stem cells. Chin J Labor Diagn 2009; 13, 300.

20. Shen YX, Wang P, Shi ED. Culturing of bone marrow mesenchymal stem cells in vitro with cerebrospinal fluid. Chin J Clin Rehab Tissue Engineer Res 2011; 15: 5 .

21. Martens W, Sanen K, Georgiou M, Struys T, Bronckaers A, Ameloot M, Phillips J, Lambrichts I. Human dental pulp stem cells can differentiate into Schwann cells and promote and guide neurite outgrowth in an aligned tissue-engineered collagen construct in vitro. FASEB J 2014; 28 (4): 1634-1643.

22. Haratizadeh S, Bojnordi MN, Niapour A, Bakhtiari M, Hamidabadi HG. Improvement of neuroglial differentiation from human dental pulp stem cells using CSF. J Mazandaran Univ Med Sci 2016; 26 (140): 1-14.

23. Mattei V, Santacroce C, Tasciotti V, Martellucci S, Santilli F, Manganelli V, Piccoli L, Misasi R, Sorice M, Garofalo T. Role of lipid rafts in neuronal differentiation of dental pulp-derived stem cells. Exp Cell Res 2015; 339 (2): 231-240.

24. Gervois P, Struys T, Hilkens P, Bronckaers A, Ratajczak J, Politis C, Brône B, Lambrichts I, Martens W. Neurogenic maturation of human dental pulp stem cells following neurosphere generation induces morphological and electrophysiological characteristics of functional neurons. Stem Cells Dev 2015; 24 (3): 296-311. 